Article

\title{
Variants of MicroRNA Genes: Gender-Specific Associations with Multiple Sclerosis Risk and Severity
}

\author{
Ivan Kiselev ${ }^{1, \dagger, *}$, Vitalina Bashinskaya ${ }^{1,2, \dagger}$, Olga Kulakova ${ }^{1,2}$, Natalia Baulina ${ }^{1}$, \\ Ekaterina Popova ${ }^{3}$, Alexey Boyko ${ }^{3}$ and Olga Favorova ${ }^{1,2}$
}

1 Dep. of Molecular Biology and Medical biotechnology, Pirogov Russian National Research Medical University, Moscow 117997, Russia; E-Mails: vitalina.bashinskaya@gmail.com (V.B.); olga.koulakova@gmail.com (O.K.); tati.90@mail.ru (N.B.); olga_favorova@mail.ru (O.F.)

2 Lab. of Functional Genomics of Cardiovascular Diseases, Russian Cardiology Research and Production Complex, Moscow 121552, Russia

3 Dep. of Neurology, Neurosurgery and Medical Genetics, Pirogov Russian National Research Medical University, Moscow 117997, Russia; E-Mails: epopova1980@yandex.ru (E.P.); boykoan13@gmail.com (A.B.)

$\dagger$ These authors contributed equally to this work.

* Author to whom correspondence should be addressed; E-Mail: kiselev.ivan.1991@gmail.com; Tel.: +7-963-678-93-51.

Academic Editor: Charles Brennan

Received: 12 July 2015 / Accepted: 14 August 2015 / Published: 24 August 2015

\begin{abstract}
Multiple sclerosis (MS) is an autoimmune neuro-inflammatory disease arising from complex interactions of genetic, epigenetic, and environmental factors. Variations in genes of some microRNAs - key post-transcriptional regulators of many genes - can influence microRNAs expression/function and contribute to MS via expression changes of protein-coding target mRNA genes. We performed an association study of polymorphous variants of MIR146A rs2910164, MIR196A2 rs11614913, MIR499A rs3746444 MIR223 rs 1044165 and their combinations with MS risk and severity. 561 unrelated patients with bout-onset MS and 441 healthy volunteers were enrolled in the study. We observed associations of MS risk with allele MIR223*T and combination (MIR223*T + MIR146A*G/G) carriage in the entire groups and in women at Bonferroni-corrected significance level $\left(p_{\text {corr }}<0.05\right)$. Besides, MIR146A* G/G association with MS was observed in women with nominal significance $\left(p_{\mathrm{f}}=0.025\right)$. No MS associations were found in men. A more severe
\end{abstract}


MS course (MSSS value > 3.5) was associated with the carriage of $M I R 499 A^{*} \mathrm{C} / \mathrm{T}$ and, less reliably, of $M I R 499 A^{*} \mathrm{C}$ ( $p_{\text {corr }}=0.006$ and $p_{\text {corr }}=0.024$, respectively) and with the carriage of combinations $\left(M I R 499 A^{*} \mathrm{C} / \mathrm{T}+M I R 196 A 2 * \mathrm{C}\right)$ and $\left(M I R 499 A^{*} \mathrm{C}+M I R 196 A 2 * \mathrm{C}\right)$ ( $p_{\text {corr }}=0.00078$ and $p_{\text {corr }}=0.0059$, respectively). These associations also showed gender specificity, as they were not significant in men and substantially reinforced in women. The strongest association with MS severity was observed in women for combination $\left(M I R 499 A^{*} \mathrm{C} / \mathrm{T}+M I R 196 A 2 * \mathrm{C}\right): p_{\text {corr }}=4.43 \times 10^{-6}$ and $\mathrm{OR}=3.23$ (CI: 1.99-5.26).

Keywords: multiple sclerosis; microRNA; SNP; association analysis; susceptibility; MSSS

\section{Introduction}

Multiple sclerosis (MS) is a chronic disease of the central nervous system, characterized by autoimmune inflammation, demyelination, and neurodegeneration [1]. MS usually affects young adults and leads to irreversible disability [2,3]. The more common course, relapsing-remitting MS (RRMS), is characterized by clinical episodes interspersed with periods of stability, affects twice as many women as men and within ten years develops into secondary progressive MS (SPMS) in 40\% of patients [4]. Together these two forms are specified as bout-onset MS, which affects approximately $85 \%-90 \%$ of patients.

Clinical phenotypes of the bout-onset MS may vary significantly, including differences in MS progression rate and severity of its clinical manifestations. Several clinical scales have been developed to distinguish individuals with relatively mild and aggressive forms of MS [5]. Among them is the Multiple Sclerosis Severity Score (MSSS) [6], which is acknowledged as the most powerful method for detecting different rates of disease progression [7] and is suitable for different epidemiologic and genetic studies [6]. Early predictors of MS's course are currently being searched.

MS is a complex disease, the development and clinical phenotypes of which result from interactions between environmental risk factors and genetic susceptibility of polygenic nature. In addition, in the past decade it became clear that epigenetic changes in susceptibility genes, influencing their expression without altering the DNA sequence, may play an essential role in MS development, possibly by mediating the effects of environmental influence [8]. The major mechanisms of epigenetic regulation are DNA methylation and histone modification, which affect the availability of DNA on transcriptional level as well as post-transcriptional gene silencing processes mediated by microRNAs (miRNAs) [9].

MiRNAs are small (19-24 nucleotides long) single-stranded non-coding RNA molecules. In accordance with the latest version of miRBase (release 21), there are more than 1800 annotated human miRNA genes [10]. MiRNAs act in the cell through imperfect base-pairing with target mRNA predominantly in $3^{\prime}$ untranslated region, thereby activating mRNA degradation or repression of its translation [11]. Being conductors of intracellular orchestra, miRNAs are key regulators of many biological processes including immune response [12]. MiRNAs can produce changes in expression of $60 \%$ of genes [13], including other miRNA genes, and thus form complicated system similar to the cytokine network, which plays a crucial role in modulation of immune response.

Even a minor shift in miRNA production may lead to significant alterations in gene expression resulting in pathological changes in the immune system. To date, diverse alterations in miRNA biogenesis 
have been observed in MS and other autoimmune diseases [14-17]. Differentially expressed miRNAs have been identified in blood elements, cerebrospinal fluid and brain lesions of MS patients [18-20].

Previous studies showed a correlation between several polymorphic variants in miRNA genes and their production levels [21,22]. Besides, common single nucleotide polymorphisms (SNPs) in several miRNAs genes were found to be associated with such autoimmune inflammatory diseases as ulcerative colitis, rheumatoid arthritis, and asthma [23-25].

Based on the assumption that genetic variation can influence miRNA expression and function, we performed an association study of miRNA gene variants with bout-onset MS risk and severity. The selection of SNPs rs2910164, rs11614913, and rs3746444 in genes MIR146A, MIR196A2, and $M I R 499 A$, respectively, was based on evidence for involvement of these miRNAs in inflammatory conditions with autoimmune components [24-26]. Importantly, the selected SNPs are located in either pre-miRNAs or mature miRNAs and this may affect their processing and/or function. We also included in the study rs 1044165 located near MIR223 since its association with MS was shown in [27] and needs to be replicated in other populations. Assuming the polygenic nature of MS, we also performed multi-locus association analysis of the studied SNPs with MS susceptibility and severity.

\section{Results}

\subsection{Analysis of Association of miRNA Genetic Variants with MS Susceptibility}

In this study, we used three statistical genetic models: the co-dominant model (effect of heterozygous genotype in comparison with the others); recessive model (effect of homozygous genotype $v s$. the others) and dominant model (effect of allele carriage, i.e., carriage of a given allele as a part of heterozygous or homozygous genotype, vs. carriage of the opposite genotype). We considered carriage of any genotype or allele of studied SNPs, which was positively associated with the phenotype, as a risk factor. We also considered as a risk factor carriage of genotype/allele combination if the latter provided a detectable cumulative effect on the phenotype (i.e., $p$-value for this combination was more significant than $p$-values for carriage of individual genotype/allele).

MIR146A, MIR196A2, and MIR499A, and MIR223 genes are located on the chromosomes 5, 12, and 20, correspondingly. Comparison of allele and genotype carriage rates of MIR146A rs2910164, MIR196A2 rs11614913, and MIR499A rs3746444 was performed for the entire groups of Russian MS patients and controls (i.e., without gender stratification) and for women and men separately. Genotype frequencies for these SNPs were in Hardy-Weinberg equilibrium in all groups of patients and healthy individuals and after their stratification by gender, except for frequencies of MIR146A SNP in male MS patients $(p<0.05)$. Results of comparison of observed miRNA genotype frequencies with expected frequencies according to the Hardy-Weinberg equilibrium are presented in Table S1.

The MIR223 gene is located in the $\mathrm{X}$ chromosome and classic biallelic genotypes of MIR223 rs 1044165 may be observed only in women. Due to this fact, association analysis for MIR223 in men and in the entire groups of MS patients and controls was performed for allele carriage only, whereas in women, genotype carriage frequencies were estimated as well. Correspondingly, compliance with Hardy-Weinberg equilibrium was evaluated only for women, and this test was passed successfully (Table S1). 
Analysis of carriage of alleles, genotypes and allelic combinations associated with MS susceptibility was performed using the APSampler algorithm. Allele/genotype carriage frequencies for each studied miRNA gene in MS patients and healthy individuals are presented in Table S2. Significant associations of SNPs in MIR499A and MIR196A2 genes with MS risk were not found. Data on genetic variants and their combinations, which were associated with MS with nominal significance at least at one type of comparison (without gender stratification, in women or in men subgroup), are presented in Table 1. Analysis of MS-associated allelic combinations revealed only one biallelic combination, consisting of $M I R 223^{*} \mathrm{~T}$ and $M I R 146 A^{*} \mathrm{G} / \mathrm{G}$, carriage of which was nominally associated with $\mathrm{MS}$ at $p_{\mathrm{f}}<0.01$ in the entire group and in women; these data are also included in Table 1.

Table 1. Positive associations of SNPs in miRNA genes with MS risk ${ }^{\dagger}$.

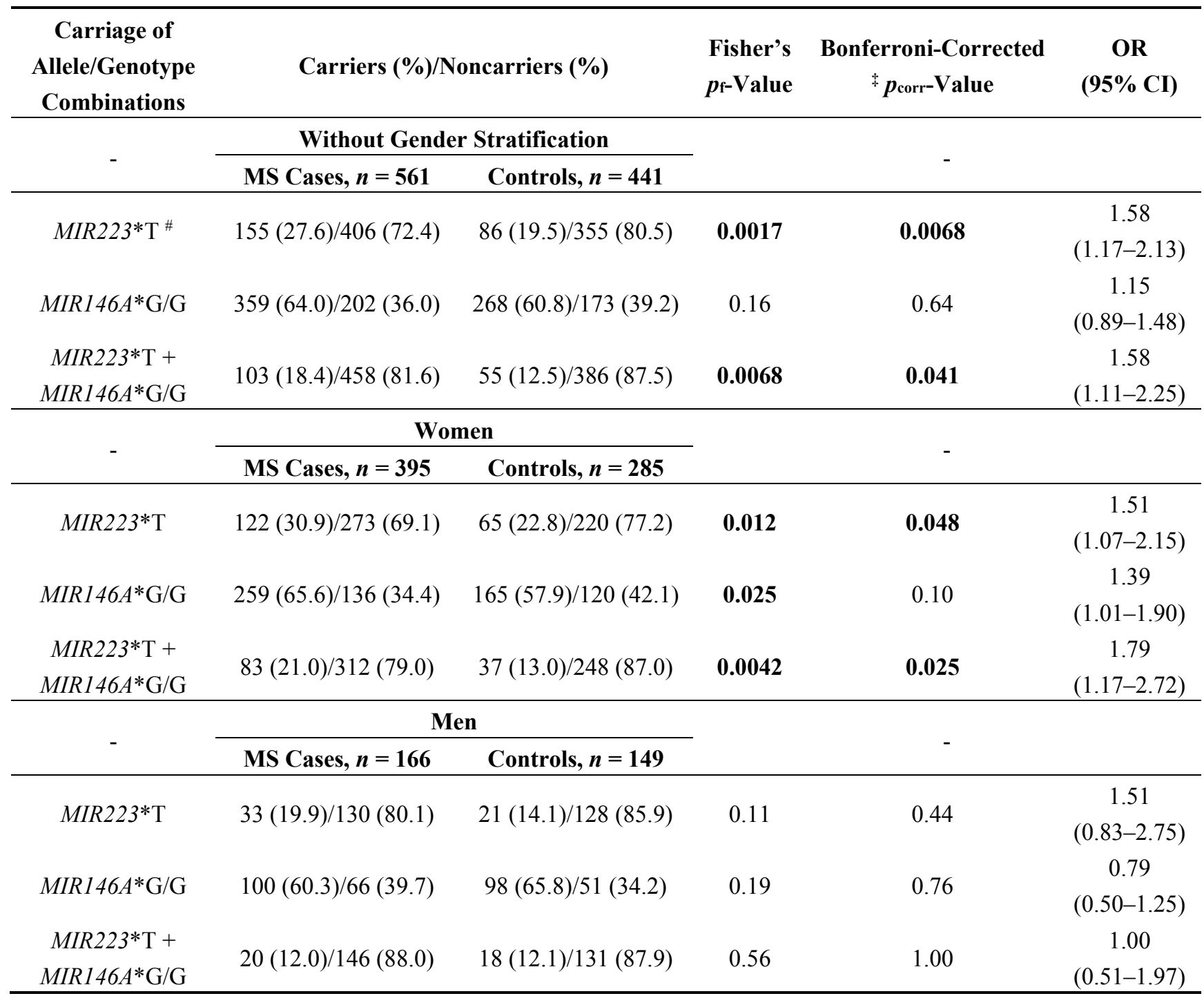

$\dagger$ Only data for the SNPs, which were significantly associated with MS at least at one of the comparisons, are presented above. Allele/genotype carriage frequencies for all genes are presented in Table S2; ${ }^{*} p$-values were corrected for 4 independent comparisons in case of single alleles/genotypes carriage and for 6 independent comparisons in case of biallelic combinations; ${ }^{*}$ Hereinafter an allele carriage rate is calculated as a sum of homozygous and heterozygous genotypes containing this allele. Significant $p_{\mathrm{f}}$ and $p_{\text {corr-values are in bold; }}$ OR_odds ratio; $\mathrm{CI}$ - confidential interval. 
Carriage of allele $M I R 223^{*} \mathrm{~T}$ by itself was found to be associated with high risk of MS development $\left(p_{\mathrm{f}}=0.0017, p_{\text {corr }}=0.0068\right.$, odds ratio $\left.(\mathrm{OR})=1.58\right)$ in the entire group, and this association remained significant in women $\left(p_{\mathrm{f}}=0.012, p_{\text {corr }}=0.048, \mathrm{OR}=1.51\right)$, but not in men after gender stratification. Genotype $M I R 146 A^{*} \mathrm{G} / \mathrm{G}$ was enriched in female patients only $\left(p_{\mathrm{f}}=0.025, \mathrm{OR}=1.39\right)$. Moreover, in women the level of significance increased if both SNPs were included in the biallelic combination $\left(M I R 223 * \mathrm{~T}+M I R 146 A^{*} \mathrm{G} / \mathrm{G}\right)\left(p_{\mathrm{f}}=0.0042, p_{\text {corr }}=0.025, \mathrm{OR}=1.79\right)$. For the entire group this combination was also significantly associated with high MS risk $\left(p_{\mathrm{f}}=0.0068, p_{\text {corr }}=0.041, \mathrm{OR}=1.58\right)$ but the $p$-value was higher than that for MIR223*T separately.

The data above show that MS is associated with MIR223*T and $\left(M I R 223 * \mathrm{~T}+M I R 146 A^{*} \mathrm{G} / \mathrm{G}\right)$ carriage in the entire groups and in women at a Bonferroni-corrected significance level $\left(p_{\text {corr }}<0.05\right)$. $M I R 146 A^{*} \mathrm{G} / \mathrm{G}$ association with MS was observed only in women with nominal significance. For men no significant results were obtained.

\subsection{Analysis of Association of miRNA Genetic Variants with MS Severity}

To estimate MS severity in individual patients, we applied the MSSS value as the most powerful indicator [6]. As shown in Table 2, such clinical features as age at onset, disease duration and mean EDSS value do not differ significantly in female and male MS patients. At the same time, MSSS values were significantly higher in men (Mann-Whitney $p$-value is 0.021). Thus, gender stratification is required in association analysis of MS severity based on MSSS.

Table 2. Clinical characteristics of bout-onset MS patients.

\begin{tabular}{cccc}
\hline Characteristics & MS Patients, $\boldsymbol{n}=\mathbf{5 6 1}$ & Women, $\boldsymbol{n}=\mathbf{3 9 5}$ & Men, $\boldsymbol{n}=\mathbf{1 6 6}$ \\
\hline Age at onset (years), mean \pm SD & $27.5 \pm 9.2$ & $27.9 \pm 9.2$ & $26.41 \pm 9.2$ \\
Disease duration (years), mean \pm SD & $11.3 \pm 7.4$ & $11.9 \pm 7.8$ & $10.1 \pm 5.0$ \\
EDSS, mean \pm SD & $2.48 \pm 1.17$ & $2.45 \pm 1.13$ & $2.54 \pm 1.26$ \\
MSSS, mean \pm SD & $3.93 \pm 1.97$ & $3.82 \pm 1.97 \dagger$ & $4.22 \pm 1.96^{\dagger}$ \\
No. of persons with RRMS/SPMS & $464 / 97$ & $329 / 66$ & $135 / 31$ \\
\hline
\end{tabular}

$\dagger$ According to the Mann-Whitney test, $p=0.021$. SD-standard deviation; RRMS-relapsing-remitting multiple sclerosis; SPMS—secondary progressive multiple sclerosis.

To search for associations of miRNA gene variants with MS severity, we divided MS patients into two groups with MSSS values $\leq 3.5$ and $>3.5$. In this way, MS patients with a relatively mild MS course, corresponding to a first three deciles of MSSS score, were compared with patients with medium and severe MS courses [28]. Allele/genotype carriage frequencies for studied miRNA genes in MS patients with MSSS values $\leq 3.5$ and $>3.5$ are presented in Table S3. Significant after Bonferroni correction association data for carriage of alleles, genotypes and identified biallelic combinations of MIR499A and MIR196A2 variants are presented in Table 3.

Carriage of $M I R 499 A^{*} \mathrm{C}$ allele $\left(p_{\text {corr }}=0.00080\right.$, odds ratio $\left.(\mathrm{OR})=2.21\right)$, especially the $M I R 499 A^{*} \mathrm{C} / \mathrm{T}$ genotype $\left(p_{\text {corr }}=2.23 \times 10^{-5}, \mathrm{OR}=2.77\right)$, is strongly associated with MS severity in women and, with a lower level of significance, in the entire group ( $p_{\text {corr }}=0.024, \mathrm{OR}=1.61$ and $p_{\text {corr }}=0.0032, \mathrm{OR}=1.85$, respectively). Biallelic combinations of these genetic variants with the $M I R 196 A 2 * \mathrm{C}$ allele are characterized by the essentially higher level of significance and higher OR values. At that, associations 
for combinations including $M I R 499 A^{*} \mathrm{C} / \mathrm{T}$ are more reliable than for those with $M I R 499 A^{*} \mathrm{C}$ and in women they are stronger than without gender stratification. Particularly, for the most significant association of $\left(M I R 499 A^{*} \mathrm{C} / \mathrm{T}+M I R 196 A 2^{*} \mathrm{C}\right)$ with $\mathrm{MS}$ severity in women $p_{\text {corr }}$ is equal to $4.43 \times 10^{-6}$ and OR reached 3.23. At the same time, no significant results were obtained in men. Polymorphic variants of MIR223 and MIR146A genes were associated with MSSS neither in the entire MS group nor upon gender stratification.

Table 3. Positive associations of SNPs in miRNA genes with the higher MS severity, evaluated by MSSS value ${ }^{\dagger}$.

\begin{tabular}{|c|c|c|c|c|c|}
\hline $\begin{array}{c}\text { Carriage of } \\
\text { Allele/Genotype } \\
\text { Combinations }\end{array}$ & \multicolumn{2}{|c|}{ Carriers $(\%) /$ Noncarriers $(\%)$} & $\begin{array}{l}\text { Fisher's } \\
p \text {-Value }\end{array}$ & $\begin{array}{c}\text { Bonferroni-Corrected } \\
p \text {-Value }\end{array}$ & $\begin{array}{c}\text { OR } \\
(95 \% \mathrm{CI})\end{array}$ \\
\hline \multirow{2}{*}{ - } & Without Gend & Stratification & & \multirow{2}{*}{-} & \\
\hline & MSSS $>3.5, n=304$ & $\operatorname{MSSS} \leq \mathbf{3 . 5}, n=242$ & & & \\
\hline$M I R 499 A^{*} \mathrm{C} / \mathrm{T}$ & $112(36.8) / 192(63.2)$ & $58(24.0) / 184(76.0)$ & 0.00081 & 0.0032 & $\begin{array}{c}1.85 \\
(1.27-2.70)\end{array}$ \\
\hline$M I R 499 A^{*} \mathrm{C}^{\#}$ & $119(39.1) / 185(60.9)$ & $69(28.5) / 173(71.5)$ & 0.0059 & 0.024 & $\begin{array}{c}1.61 \\
(1.12-2.32)\end{array}$ \\
\hline $\begin{array}{c}\text { MIR499A* } \mathrm{C} / \mathrm{T}+ \\
\text { MIR196A2*C }\end{array}$ & $101(33.2) / 203(66.8)$ & $46(19.0) / 196(81.0)$ & 0.00013 & 0.00078 & $\begin{array}{c}2.12 \\
(1.42-3.16)\end{array}$ \\
\hline $\begin{array}{l}M I R 499 A^{*} \mathrm{C}+ \\
M I R 196 A 2 * \mathrm{C} \\
\end{array}$ & $107(35.2) / 197(64.8)$ & $55(22.7) / 187(77.3)$ & 0.00099 & 0.0059 & $\begin{array}{c}1.85 \\
(1.26-2.71) \\
\end{array}$ \\
\hline \multirow{2}{*}{ - } & \multicolumn{2}{|c|}{ Women } & & & \\
\hline & MSSS $>\mathbf{3 . 5}, n=207$ & $\operatorname{MSSS} \leq 3.5, n=181$ & & & \\
\hline$M I R 499 A^{*} \mathrm{C} / \mathrm{T}$ & $86(41.5) / 121(58.5)$ & $37(20.4) / 144(79.6)$ & $5.58 \times 10^{-6}$ & $2.23 \times 10^{-5}$ & $\begin{array}{c}2.77 \\
(1.76-4.36)\end{array}$ \\
\hline MIR $499 A^{*} \mathrm{C}$ & $89(43.0) / 118(57.0)$ & $46(25.4) / 135(74.6)$ & 0.00020 & 0.00080 & $\begin{array}{c}2.21 \\
(1.44-3.41)\end{array}$ \\
\hline $\begin{array}{c}M I R 499 A^{*} \mathrm{C} / \mathrm{T}+ \\
M I R 196 A 2 * \mathrm{C}\end{array}$ & $79(38.2) / 128(61.8)$ & $29(16.0) / 152(84.0)$ & $7.38 \times 10^{-7}$ & $4.43 \times 10^{-6}$ & $\begin{array}{c}3.23 \\
(1.99-5.26)\end{array}$ \\
\hline $\begin{array}{l}M I R 499 A^{*} \mathrm{C}+ \\
M I R 196 A 2 * \mathrm{C} \\
\end{array}$ & $81(39.1) / 126(60.9)$ & $37(20.4) / 144(79.6)$ & $4.5 \times 10^{-5}$ & 0.00027 & $\begin{array}{c}2.50 \\
(1.58-3.95) \\
\end{array}$ \\
\hline \multirow{2}{*}{ - } & \multicolumn{2}{|c|}{ Men } & & & \\
\hline & MSSS $>$ 3.5, $n=97$ & $\operatorname{MSSS} \leq 3.5, n=61$ & & & \\
\hline$M I R 499 A^{*} \mathrm{C} / \mathrm{T}$ & $26(26.8) / 71(73.2)$ & $21(34.4) / 40(65.6)$ & 0.2 & 0.80 & $\begin{array}{c}0.70 \\
(0.35-1.40)\end{array}$ \\
\hline MIR $499 A^{*} \mathrm{C}$ & $30(30.9) / 67(69.1)$ & $23(37.8) / 38(62.2)$ & 0.24 & 0.96 & $\begin{array}{c}0.74 \\
(0.38-1.45)\end{array}$ \\
\hline $\begin{array}{c}\text { MIR499A* } \mathrm{C} / \mathrm{T}+ \\
\text { MIR196A2*C }\end{array}$ & $7(7.2) / 90(92.8)$ & $8(13.1) / 53(86.9)$ & 0.17 & 1.00 & $\begin{array}{c}0.52 \\
(0.17-1.50)\end{array}$ \\
\hline $\begin{array}{l}\text { MIR } 499 A^{*} \mathrm{C}+ \\
M I R 196 A 2 * \mathrm{C}\end{array}$ & $26(26.8) / 71(73.2)$ & $18(29.5) / 43(70.5)$ & 0.42 & 1.00 & $\begin{array}{c}0.87 \\
(0.43-1.78)\end{array}$ \\
\hline
\end{tabular}

$\dagger$ Only data for the SNPs, which were significantly associated with MSSS value at least at one of the comparisons, are presented above. Allele/genotype carriage frequencies for all genes are presented in Table S3; ${ }^{\star} p$-values were corrected using Bonferroni correction for 4 independent comparisons for single alleles/genotypes carriage and for 6 independent comparisons for biallelic combinations; ${ }^{*}$ Hereinafter an allele carriage rate is calculated as a sum of homozygous and heterozygous genotypes containing this allele.

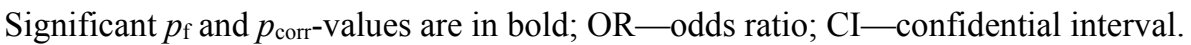


We compared also MSSS values in carriers and noncarriers of $M I R 499 A^{*} \mathrm{C} / \mathrm{T}$ and $M I R 499 A^{*} \mathrm{C}$ by itself and in combinations with $M I R 196 A 2^{*} \mathrm{C}$. Significant differences in average MSSS values were found for carriers and noncarriers of MIR $499 A^{*} \mathrm{C} / \mathrm{T}, M I R 499 A^{*} \mathrm{C},\left(M I R 499 A^{*} \mathrm{C} / \mathrm{T}+M I R 196 A 2 * \mathrm{C}\right)$ and $\left(M I R 499 A^{*} \mathrm{C}+M I R 196 A 2^{*} \mathrm{C}\right)$ in the entire group (Mann-Whitney $p$-values are equal to $0.0085,0.028$, 0.0062 and 0.023 , respectively). Again, these differences were greater among women $(p=0.0004$, $p=0.0039, p=0.0003$, and $p=0.0048$, respectively) (Table 4). As expected, in men MSSS was not significantly associated with carriage of these variants.

Thus, carriage of the MIR499A C/T genotype or $\mathrm{C}$ allele by themselves and in combination with MIR 196A2*C is strongly associated with high MS severity, estimated by the Multiple Sclerosis Severity Score. This association is women-specific.

Table 4. Comparison of MSSS values between carriers and noncarriers of genetic variants associated with MS severity.

\begin{tabular}{cccccc}
\hline & \multicolumn{2}{c}{ Carriers } & \multicolumn{2}{c}{ Noncarriers } & Mann-Whitney \\
Group of Patients & $\begin{array}{c}\text { No. of Persons } \\
(\mathbf{\%})\end{array}$ & $\begin{array}{c}\text { MSSS, } \\
\text { Mean } \pm \text { SD }\end{array}$ & $\begin{array}{c}\text { No. of Persons } \\
\mathbf{( \% )}\end{array}$ & $\begin{array}{c}\text { MSSS, } \\
\text { Mean } \pm \text { SD }\end{array}$ & $\boldsymbol{p}$-Value \\
\hline All persons & $170(31.1)$ & $4.23 \pm 1.92$ & $376(68.9)$ & $3.80 \pm 1.98$ & $\mathbf{0 . 0 0 8 5}$ \\
Women & $123(31.7)$ & $4.30 \pm 1.97$ & $265(68.3)$ & $3.60 \pm 1.93$ & $\mathbf{0 . 0 0 0 4}$ \\
Men & $47(29.7)$ & $4.04 \pm 1.80$ & $111(70.3)$ & $4.30 \pm 2.03$ & 0.57 \\
\hline All persons & $188(34.4)$ & $4.16 \pm 1.93$ & $358(65.6)$ & $3.81 \pm 1.98$ & $\mathbf{0 . 0 2 8}$ \\
Women & $135(34.8)$ & $4.19 \pm 1.97$ & $253(65.2)$ & $3.62 \pm 1.94$ & $\mathbf{0 . 0 0 3 9}$ \\
Men & $53(33.5)$ & $4.11 \pm 1.85$ & $105(66.5)$ & $4.28 \pm 2.02$ & 0.70 \\
\hline All persons & $147(26.9)$ & $4.27 \pm 1.93$ & $399(73.1)$ & $3.81 \pm 1.97$ & $\mathbf{0 . 0 0 6 2}$ \\
Women & $108(27.8)$ & $4.36 \pm 1.96$ & $280(72.2)$ & $3.61 \pm 1.93$ & $\mathbf{0 . 0 0 0 3}$ \\
Men & $39(24.7)$ & $4.04 \pm 1.85$ & $119(75.3)$ & $4.28 \pm 2.00$ & 0.61 \\
\hline All persons & $162(29.7)$ & $4.20 \pm 1.96$ & $384(70.3)$ & $3.82 \pm 1.97$ & \\
Women & $118(30.4)$ & $4.21 \pm 1.98$ & $270(69.6)$ & $3.64 \pm 1.94$ & $\mathbf{0 . 0 2 3}$ \\
Men & $44(27.8)$ & $4.17 \pm 1.91$ & $114(72.2)$ & $4.24 \pm 1.99$ & 0.92 \\
\hline
\end{tabular}

Significant $p$-values are in bold.

\section{Discussion}

In the present study, we performed an association study of four miRNA genetic variants with MS susceptibility and severity in Russians. We identified the involvement of polymorphous variants of two miRNA genes-MIR223 and MIR146A-in MS susceptibility and of two other miRNA genes - MIR499A and MIR196A2 - in the MS course. In all cases, significant associations were observed in the entire group and in women but not in men, showing gender specificity.

We found that allele MIR 223*T carriage is associated with MS susceptibility in Russians, maintaining the Bonferroni correction. Previously, rs1044165 in MIR223 was shown to be associated with MS in Italians [27], though with the opposite direction of association, and the microRNA was down-regulated in the serum of MS patients [14]. 
The MIR223 gene is located on the $\mathrm{X}$ chromosome. X chromosome copy number difference among men and women results in difficulties with association studies of SNPs located on it. If the analysis is performed in mixed-gender groups, male SNP genotypes may be set either as homozygous female (resulting in three genotypes in the total sample) or as unique (hemizygous) ones (five genotypes in total). Such approaches are available only if female/male ratios in studied groups are equal, otherwise the resulting associations with SNP genotypes can be confounded by differences in the sex ratio [29]. Search for associations in gender-stratified groups seems to be the most appropriate, though it leads to loss of statistical power because of the decreasing number of individuals. Unfortunately, in the study [27] no data on sex ratio in the control group were provided, and, to our knowledge, gender stratification was not performed. In the present study, to reduce a possible sex bias, we analyzed women and men separately, in addition to analysis of the entire group, to search for gender-specific associations. Only carriage rates of MIR223 alleles in the entire group and men were compared, while genotype frequencies were considered as well in women separately.

Inconsistency of obtained results with data in an Italian study may be explained also by involvement of different mechanisms to MS pathogenesis in various ethnic groups. rs1044165, being in a linkage disequilibrium (LD) block with MIR223, is located within VSIG4 gene, which acts as a strong inhibitor of T cell activation [30]. Thus we may suggest opposite SNP alleles to influence MS pathogenesis through the effects of different genes in various populations, acknowledging different LD patterns in them.

In addition to MIR223 by itself, we found an association of biallelic combination $\left(M I R 223 * \mathrm{~T}+\operatorname{MIR} 146 A^{*} \mathrm{G} / \mathrm{G}\right)$ with $\mathrm{MS}$ susceptibility in women. This combination satisfies the requirement of the minimal set (combination) of alleles as a genetic risk factor, which means that a combination is associated with the phenotype more reliably (e.g., with better $p$-value) than each of its components [31]. Meanwhile, the same combination cannot be considered a minimal set in the entire group, though it is nominally significant and withstands the Bonferroni correction, since the significance level of association of MIR223*T by itself $\left(p_{\text {corr }}=0.0068\right)$ is lower than that of the combination $\left(p_{\text {corr }}=0.041\right)$. Besides, MIR $146 A^{*} \mathrm{G} / \mathrm{G}$ by itself was nominally associated with $\mathrm{MS}$ in women (uncorrected $p_{\mathrm{f}}$-value $=0.025$ ), so the role of $M I R 146 \mathrm{~A}$ in MS seems to be clarified with a larger sample size and in populations of other descent.

rs2910164 is located in pre-miR-146a, and G allele carriage leads to increased mature miR-146a production due to more effective pri-miR-146a processing in nucleus and more effective nuclear pore complex binding [22]. Results of recent MS association studies of MIR146A gene polymorphism are conflicting. Association of MIR146A rs2910164 with MS was not observed in Italians [14], whereas the $\mathrm{C}$ allele at this SNP was significantly enriched in Chinese female patients [32]. Such contradictory results can be at least partially explained by large discrepancies in allele frequencies in these populations and even contradictory effects of these alleles on gene expression [32] due to the different evolutionary history of the populations studied to date. In line with emerging data indicating a role of this gene and of the mature miRNA in MS, the same SNP was associated with susceptibility to Behcet's disease [26], with a clinical phenotype of systemic lupus erythematosus [33] and Alzheimer's disease [34]. At the same time, no associations were identified for rs2910164 with type 2 diabetes susceptibility in Italians [35] nor with systemic lupus erythematosus or juvenile rheumatoid arthritis in Mexicans [24]. MIR 146A was suggested to play a role in astrocyte-mediated inflammatory response [36] and to be a part of Th17 pathway [37]. 
This work also aimed to study the role of miRNA genes as genetic risk factors in MS severity. Finding an adequate measure of this clinical phenotype that enables robust characterization of an individual's MS course and is applicable to stratification of MS patients in epidemiologic and genetic studies is a serious challenge. Among the first severity criteria was EDSS, a scale which allows the estimation of a neurological patient's disability at a given period [38]. EDSS as well as other characteristics of current state, e.g., accumulation of brain lesions on MRI, are time-dependent and have to be corrected for disease duration to compare patients [39]. For this purpose, different approaches have been applied in genetic studies - time to reach certain EDSS values [40,41] and the progression index $[42,43]$, that is, the number of EDSS points reached at a given time - but these characteristics do not account for non-linear MS progression. The MSSS value, which relates EDSS to MS duration and compares these characteristics with MS courses in other individuals [6], is probably the optimal tool to measure MS severity, applicable to genetic studies.

We compared allele/genotype/allelic combinations carriage rates of the studied genes in MS patients stratified by their MSSS values. We put the threshold of severe MS course at MSSS value 3.5. This is in accordance with MSSS levels compared in other studies [7,28] and is very close to the median MSSS value in our sample. Analysis was performed separately for male and female patients. This was reasonable, accounting for difference in their MSSS values as well as the observed fact of gender specificity in associations of miRNA genetic variance with MS susceptibility.

Carriage of the MIR 499A* $\mathrm{C} / \mathrm{T}$ genotype and the biallelic combination $\left(M I R 499 A^{*} \mathrm{C} / \mathrm{T}+M I R 196 A 2 * \mathrm{C}\right)$ were strongly associated with an MSSS value $>3.5$, i.e., with a severe MS course. Of note is that the significance levels of these associations in women $\left(p_{\text {corr }}=2.23 \times 10^{-5}\right.$ and $4.43 \times 10^{-6}$, correspondingly) were higher than in the entire group ( $p_{\text {corr }}=0.0032$ and 0.00078 , correspondingly). If we consider the carriage of the MIR499A*C allele and the combination $\left(M I R 499 A^{*} \mathrm{C}+M I R 196 A 2^{*} \mathrm{C}\right)$, the observed significance levels substantially decrease in comparison with of the $M I R 499 A^{*} \mathrm{C} / \mathrm{T}$ genotype by itself and in combination with $M I R 196 A 2 * \mathrm{C}$. Both combinations $\left(M I R 499 A^{*} \mathrm{C} / \mathrm{T}+M I R 196 A 2 * \mathrm{C}\right)$ and $\left(M I R 499 A^{*} \mathrm{C}+M I R 196 A 2 * \mathrm{C}\right)$ satisfy the requirement of the minimal predisposing set of alleles in the entire group and in women. Association of identified genetic variants with MS severity was confirmed using the Mann-Whitney test: their carriers have significantly higher MSSS values ( $p=0.028-0.0003)$ both among women and in the entire group. At the same time no associations with MS severity were found in men.

The observed ORs for miRNA genetic variance associations with MS severity are quite high. They lay in ranges from 1.61 to 2.12 in the entire group and from 2.21 to 3.23 in women. Such strong effect ranges are not common for complex diseases. The fact that the highest ORs and the lowest $p$-values in this study are obtained for a heterozygous genotype at MIR499A rs3746444 corresponds to the codominant genetic model.

rs3746444, located in pre-miR-499a, was previously found to be associated with several autoimmune diseases. Different alleles and genotypes of this gene were significantly associated with rheumatoid arthritis in Iranians [23], ulcerative colitis in Japanese [25], Behcet's disease in Turks [26], and with a severe and more active phenotype of rheumatoid arthritis in Egyptian female patients [44]. Of note is that the most significant associations in the two latter cases were found for the $\mathrm{C} / \mathrm{T}$ genotype, which reinforces the evidence for possible codominant interaction between MIR 499A alleles. 
rs11614913*T in the MIR196A2 gene was shown to increase mature miR-196a2 expression and to influence its targets binding [21]. This allele has been previously associated with severe clinical phenotype of colitis in Japanese patients [25] and with higher risk of Bechet's disease in Chinese patients [45]. rs11614913 is also a cis-eQTL for SMUG1 gene [46,47], which encodes a base excision repair enzyme, involved in checkpoint regulation of the cell cycle and DNA reparation.

In all cases significant associations with MS susceptibility and severity were identified in women but not in men. Furthermore, in most instances the significance levels of these associations in women are up to several orders higher than in more numerous entire groups including both men and women. Association of $M I R 223^{*} \mathrm{~T}$ allele carriage with MS risk was the only exception, being more significant in the entire group than in women, but location of this gene on the $\mathrm{X}$ chromosome did not favor analysis of gender effects. Given the above, there is every reason to suppose that the studied microRNA variants show gender specificity and are not associated with MS risk and severity in men.

Such gender-dependent effects of polymorphisms of miRNA genes on disease susceptibility and clinical features may be explained by variations in endocrine profiles between men and women. It was previously shown that estrogen treatment influences on expression of studied here mir-146a, miR-196a2 and miR-223 genes $[48,49]$. Thus, estrogen-dependent difference in miRNA activity may modify the effect of polymorphisms on MS risk and severity and lead to gender specificity.

Using multi-locus association analysis, we observed in this study the moderate cumulative effect of MIR223 and MIR146A genetic variants on MS susceptibility in women and the more strongly expressed cumulative effect of MIR499A and MIR196A2 on MS course both in the entire group and in women. The joint contribution of two miRNA genes may arise from their additive effect or from possible modifying effect (epistasis) of the gene by the other gene. One way or another, observed interactions of miRNA genes may reflect their pairwise involvement in different pathways of the miRNA regulatory network.

\section{Experimental Section}

\subsection{Patients and Controls}

Five hundred sixty-one unrelated patients with bout-onset MS diagnosed according to the McDonald Criteria [50] were enrolled in the study (395 women, 166 men; mean age $38.7 \pm 10.7$ years). 464 patients suffered from RRMS and 97 from SPMS. Retrospectively collected clinical data also included age of MS onset, disease duration, EDSS value [38], and MSSS calculated according to the Global MSSS table [6] and measured before starting therapy.

The control group consisted of 441 volunteers with no sign of neurological disorders (mean age $44.4 \pm 16$ years). Among them there were 285 women and 149 men whereas for 7 individuals gender was unknown. All MS patients and healthy individuals lived in the Moscow region and self-reported as Russians. The study was approved by the local ethics committee, and written informed consent had been obtained from each patient.

\subsection{Genotyping}

Extraction of genomic DNA from whole or frozen blood samples was performed either with modified phenol-chloroform method [51] or using QIAamp DNA Blood Midi Kits from Qiagen (Hilden, 
Germany). Real-time PCR with pre-designed TaqMan kits from Life Technologies (Foster City, CA, USA) was used for genotyping of SNPs in miRNA genes: MIR499A rs3746444, MIR223 rs1044165, MIR196A2 rs11614913, MIR146A rs2910164.

\subsection{Statistical Analysis}

Observed genotype frequencies were compared by $\chi^{2}$ criteria (the significance level set at 0.05 ) with expected genotype proportions calculated according to the Hardy-Weinberg equilibrium. The Mann-Whitney test was used to evaluate the differences in MS clinical features in various groups of patients.

Alleles, genotypes and combinations of alleles of different loci, carriage of which was associated with MS risk and severity, along with the direction of each association, were identified using the APSampler algorithm [52]. The findings were then validated by standard statistical approaches: calculation of OR and 95\% CI and the exact Fisher's $p$-value $\left(p_{\mathrm{f}}\right)$ using the tools included in the APSampler software [53]. In this case, we applied a one-sided Fisher's test for the validation procedure, as the direction of association for each pattern to be validated was already known. We considered MS association with a single allele/genotype to be nominally significant, if $p_{\mathrm{f}}$ was $<0.05$, and with allelic combinations, if $p_{\mathrm{f}}$ was $<0.01$. In all cases we required that the $95 \%$ CI for OR did not cross 1 . All genetic variants were considered to be significantly associated with a studied phenotype if their Bonferroni-corrected exact Fisher's test $p$-values $\left(p_{\text {corr }}\right)$ were $<0.05$.

\section{Conclusions}

We found that SNPs in MIR223 and MIR146A are involved in MS susceptibility, whereas SNPs in MIR499A and MIR196A2 are involved in the MS course. Multi-locus association analysis has shown pairwise interactions of MIR223 with MIR146A and MIR499A with MIR196A2. The distinct roles of the studied miRNA variants in MS risk and severity may indicate divergent regulatory networks to be involved in the development of MS and in formation of a severe clinical phenotype in patients. Significant associations of miRNA genes' variants were gender-specific, having been identified in women but not in men. However, replication of the obtained results in individuals of the same and of other ancestries is the next necessary study stage.

\section{Supplementary Materials}

Supplementary materials can be found at http://www.mdpi.com/1422-0067/16/08/20067/s1.

\section{Acknowledgments}

This study was supported by the Russian Science Foundation (grant 14-14-00605). The authors would like to thank Prof. Olga Mustafina (Institute of Biochemistry and Genetics, Ufa Research Center, Ufa, Russia) who kindly helped us to enlarge the collection of DNA samples of healthy individuals.

\section{Author Contributions}

Ivan Kiselev and Vitalina Bashinskaya performed the experiments; Ivan Kiselev and Olga Kulakova analysed the data; Olga Kulakova and Olga Favorova coordinated the study; Ekaterina Popova provided 
blood samples of MS patients and their clinical data; Alexey Boyko analyzed clinical data and selected criteria for patients stratification; Ivan Kiselev, Vitalina Bashinskaya and Natalia Baulina wrote the manuscript; Olga Favorova performed critical revision of the manuscript.

\section{Conflicts of Interest}

The authors declare no conflict of interest.

\section{References}

1. Bruck, W. The pathology of multiple sclerosis is the result of focal inflammatory demyelination with axonal damage. J. Neurol. 2005, 252 (Suppl. 5), v3-v9.

2. Ponzio, M.; Brichetto, G.; Zaratin, P.; Battaglia, M.A. Workers with disability: The case of multiple sclerosis. Neurol. Sci. 2015, 1-7, doi:10.1007/s10072-015-2265-3.

3. Racosta, J.M.; Kimpinski, K.; Morrow, S.A.; Kremenchutzky, M. Autonomic dysfunction in multiple sclerosis. Auton. Neurosci. 2015, doi:10.1016/j.autneu.2015.06.001.

4. Iwanowski, P.; Losy, J. Immunological differences between classical phenothypes of multiple sclerosis. J. Neurol. Sci. 2015, 349, 10-14.

5. Ransohoff, R.M.; Hafler, D.A.; Lucchinetti, C.F. Multiple sclerosis-A quiet revolution. Nat. Rev. Neurol. 2015, 11, 134-142.

6. Roxburgh, R.H.; Seaman, S.R.; Masterman, T.; Hensiek, A.E.; Sawcer, S.J.; Vukusic, S.; Achiti, I.; Confavreux, C.; Coustans, M.; le Page, E.; et al. Multiple Sclerosis Severity Score: Using disability and disease duration to rate disease severity. Neurology 2005, 64, 1144-1151.

7. Bergamaschi, R.; Montomoli, C.; Mallucci, G.; Lugaresi, A.; Izquierdo, G.; Grand'Maison, F.; Duquette, P.; Shaygannejad, V.; Alroughani, R.; Grammond, P.; et al. BREMSO: A simple score to predict early the natural course of multiple sclerosis. Eur. J. Neurol. 2015, 22, 981-989.

8. Oksenberg, J.R. Decoding multiple sclerosis: An update on genomics and future directions. Expert Rev. Neurother. 2013, 13 (Suppl. 12), 11-19.

9. Koch, M.W.; Metz, L.M.; Kovalchuk, O. Epigenetic changes in patients with multiple sclerosis. Nat. Rev. Neurol. 2013, 9, 35-43.

10. miRBase. Available online: http://www.mirbase.org/ (accessed on 1 July 2015).

11. Ha, T.Y. MicroRNAs in human diseases: From cancer to cardiovascular disease. Immune Netw. 2011, 11, 135-154.

12. Gracias, D.T.; Katsikis, P.D. MicroRNAs: Key components of immune regulation. Adv. Exp. Med. Biol. 2011, 780, 15-26.

13. Diao, L.; Marcais, A.; Norton, S.; Chen, K.C. MixMir: MicroRNA motif discovery from gene expression data using mixed linear models. Nucleic Acids Res. 2014, 42, e135.

14. Fenoglio, C.; Cantoni, C.; de Riz, M.; Ridolfi, E.; Cortini, F.; Serpente, M.; Villa, C.; Comi, C.; Monaco, F.; Mellesi, L.; et al. Expression and genetic analysis of miRNAs involved in CD4+ cell activation in patients with multiple sclerosis. Neurosci. Lett. 2011, 504, 9-12.

15. Long, L.; Yu, P.; Liu, Y.; Wang, S.; Li, R.; Shi, J.; Zhang, X.; Li, Y.; Sun, X.; Zhou, B.; et al. Upregulated microRNA-155 expression in peripheral blood mononuclear cells and fibroblast-like synoviocytes in rheumatoid arthritis. Clin. Dev. Immunol. 2013, 296139, doi:10.1155/2013/296139. 
16. Lv, Y.; Qi, R.; Xu, J.; Di, Z.; Zheng, H.; Huo, W.; Zhang, L.; Chen, H.; Gao, X. Profiling of serum and urinary microRNAs in children with atopic dermatitis. PLOS ONE 2014, 9, e115448.

17. Zhu, J.; Huang, X.; Su, G.; Wang, L.; Wu, F.; Zhang, T.; Song, G. High expression levels of microRNA-629, microRNA-525-5p and microRNA-516a-3p in paediatric systemic lupus erythematosus. Clin. Rheumatol. 2014, 33, 807-815.

18. Haghikia, A.; Haghikia, A.; Hellwig, K.; Baraniskin, A.; Holzmann, A.; Decard, B.F.; Thum, T.; Gold, R., Regulated microRNAs in the CSF of patients with multiple sclerosis: A case-control study. Neurology 2012, 79, 2166-2170.

19. Junker, A.; Krumbholz, M.; Eisele, S.; Mohan, H.; Augstein, F.; Bittner, R.; Lassmann, H.; Wekerle, H.; Hohlfeld, R.; Meinl, E. MicroRNA profiling of multiple sclerosis lesions identifies modulators of the regulatory protein CD47. Brain 2009, 132, 3342-3352.

20. Keller, A.; Leidinger, P.; Lange, J.; Borries, A.; Schroers, H.; Scheffler, M.; Lenhof, H.P.; Ruprecht, K.; Meese, E., Multiple sclerosis: MicroRNA expression profiles accurately differentiate patients with relapsing-remitting disease from healthy controls. PLOS ONE 2009, 4, e7440.

21. Hu, Z.; Chen, J.; Tian, T.; Zhou, X.; Gu, H.; Xu, L.; Zeng, Y.; Miao, R.; Jin, G.; Ma, H.; et al. Genetic variants of miRNA sequences and non-small cell lung cancer survival. J. Clin. Investig. 2008, 118, 2600-2608.

22. Jazdzewski, K.; Murray, E.L.; Franssila, K.; Jarzab, B.; Schoenberg, D.R.; de la Chapelle, A. Common SNP in pre-miR-146a decreases mature miR expression and predisposes to papillary thyroid carcinoma. Proc. Nat. Acad. Sci. USA 2008, 105, 7269-7274.

23. Hashemi, M.; Eskandari-Nasab, E.; Zakeri, Z.; Atabaki, M.; Bahari, G.; Jahantigh, M.; Taheri, M.; Ghavami, S. Association of pre-miRNA-146a rs2910164 and premiRNA-499 rs3746444 polymorphisms and susceptibility to rheumatoid arthritis. Mol. Med. Rep. 2013, 7, 287-291.

24. Jimenez-Morales, S.; Gamboa-Becerra, R.; Baca, V.; del Rio-Navarro, B.E.; Lopez-Ley, D.Y.; Velazquez-Cruz, R.; Saldana-Alvarez, Y.; Salas-Martinez, G.; Orozco, L. MiR-146a polymorphism is associated with asthma but not with systemic lupus erythematosus and juvenile rheumatoid arthritis in Mexican patients. Tissue Antigens 2012, 80, 317-321.

25. Okubo, M.; Tahara, T.; Shibata, T.; Yamashita, H.; Nakamura, M.; Yoshioka, D.; Yonemura, J.; Kamiya, Y.; Ishizuka, T.; Nakagawa, Y.; et al. Association study of common genetic variants in pre-microRNAs in patients with ulcerative colitis. J. Clin. Immunol. 2011, 31, 69-73.

26. Oner, T.; Yenmis, G.; Tombulturk, K.; Cam, C.; Kucuk, O.S.; Yakicier, M.C.; Dizman, D.; Sultuybek, G.K. Association of pre-miRNA-499 rs3746444 and pre-miRNA-146a rs2910164 polymorphisms and susceptibility to Behcet's disease. Genet. Test. Mol. Biomark. 2015, 19, 424-430.

27. Ridolfi, E.; Fenoglio, C.; Cantoni, C.; Calvi, A.; de Riz, M.; Pietroboni, A.; Villa, C.; Serpente, M.; Bonsi, R.; Vercellino, M.; et al. Expression and genetic analysis of microRNAs involved in multiple sclerosis. Int. J. Mol. Sci. 2013, 14, 4375-4384.

28. Cierny, D.; Hanysova, S.; Michalik, J.; Kantorova, E.; Kurca, E.; Skerenova, M.; Lehotsky, J. Genetic variants in interleukin 7 receptor $\alpha$ chain (IL-7Ra) are associated with multiple sclerosis risk and disability progression in Central European Slovak population. J. Neuroimmunol. 2015, 282, $80-84$.

29. Clayton, D.G. Sex chromosomes and genetic association studies. Genome Med. 2009, 1, 110. 
30. Vogt, L.; Schmitz, N.; Kurrer, M.O.; Bauer, M.; Hinton, H.I.; Behnke, S.; Gatto, D.; Sebbel, P.; Beerli, R.R.; Sonderegger, I.; et al. VSIG4, a B7 family-related protein, is a negative regulator of T cell activation. J. Clin. Investig. 2006, 116, 2817-2826.

31. Lvovs, D.; Favorova, O.O.; Favorov, A.V. A polygenic approach to the study of polygenic diseases. Acta Naturae 2012, 4, 59-71.

32. Li, Y.; Du, C.; Wang, W.; Ma, G.; Cui, L.; Zhou, H.; Tao, H.; Yao, L.; Zhao, B.; Li, K. Genetic association of MiR-146a with multiple sclerosis susceptibility in the Chinese population. Cell. Physiol. Biochem. 2015, 35, 281-291.

33. Ciccacci, C.; Perricone, C.; Ceccarelli, F.; Rufini, S.; Di Fusco, D.; Alessandri, C.; Spinelli, F. R.; Cipriano, E.; Novelli, G.; Valesini, G.; et al. A multilocus genetic study in a cohort of Italian SLE patients confirms the association with STAT4 gene and describes a new association with HCP5 gene. PLoS ONE 2014, 9, e111991.

34. Zhang, B.; Wang, A.; Xia, C.; Lin, Q.; Chen, C. A single nucleotide polymorphism in primarymicroRNA146a reduces the expression of mature microRNA146a in patients with Alzheimer's disease and is associated with the pathogenesis of Alzheimer's disease. Mol. Med. Rep. 2015, 12, 4037-4042.

35. Ciccacci, C.; di Fusco, D.; Cacciotti, L.; Morganti, R.; D’Amato, C.; Greco, C.; Rufini, S.; Novelli, G.; Sangiuolo, F.; Spallone, V.; et al. MicroRNA genetic variations: Association with type 2 diabetes. Acta Diabetol. 2013, 50, 867-872.

36. Iyer, A.; Zurolo, E.; Prabowo, A.; Fluiter, K.; Spliet, W.G.; van Rijen, P.C.; Gorter, J.A.; Aronica, E. MicroRNA-146a: A key regulator of astrocyte-mediated inflammatory response. PLOS ONE 2012, 7, e44789.

37. Omrane, I.; Benammar-Elgaaied, A. The immune microenvironment of the colorectal tumor: Involvement of immunity genes and microRNAs belonging to the TH17 pathway. Biochim. Biophys. Acta 2015, 1856, 28-38.

38. Kurtzke, J.F. Rating neurologic impairment in multiple sclerosis: An expanded disability status scale (EDSS). Neurology 1983, 33, 1444-1452.

39. Depaz, R.; Granger, B.; Cournu-Rebeix, I.; Bouafia, A.; Fontaine, B. Genetics for understanding and predicting clinical progression in multiple sclerosis. Rev. Neurol. 2011, 167, 791-801.

40. Harding, K.; Ingram, G.; Cossburn, M.; Hirst, C.; Pickersgill, T.; Ben-Shlomo, Y.; Robertson, N. Genotype-phenotype correlation for non-HLA disease associated risk alleles in multiple sclerosis. Neurosci. Lett. 2012, 526, 15-19.

41. Schmied, M.C.; Zehetmayer, S.; Reindl, M.; Ehling, R.; Bajer-Kornek, B.; Leutmezer, F.; Zebenholzer, K.; Hotzy, C.; Lichtner, P.; Meitinger, T.; et al. Replication study of multiple sclerosis (MS) susceptibility alleles and correlation of DNA-variants with disease features in a cohort of Austrian MS patients. Neurogenetics 2012, 13, 181-187.

42. Kikuchi, S.; Fukazawa, T.; Niino, M.; Yabe, I.; Miyagishi, R.; Hamada, T.; Tashiro, K. Estrogen receptor gene polymorphism and multiple sclerosis in Japanese patients: Interaction with HLA-DRB1*1501 and disease modulation. J. Neuroimmunol. 2002, 128, 77-81.

43. Niino, M.; Kikuchi, S.; Fukazawa, T.; Yabe, I.; Tashiro, K. Polymorphisms of apolipoprotein E and Japanese patients with multiple sclerosis. Mult. Scler. 2003, 9, 382-386. 
44. El-Shal, A.S.; Aly, N.M.; Galil, S.M.; Moustafa, M.A.; Kandel, W.A. Association of microRNAs genes polymorphisms with rheumatoid arthritis in Egyptian female patients. Jt. Bone Spine 2013, $80,626-631$.

45. Qi, J.; Hou, S.; Zhang, Q.; Liao, D.; Wei, L.; Fang, J.; Zhou, Y.; Kijlstra, A.; Yang, P. A functional variant of pre-miRNA-196a2 confers risk for Behcet's disease but not for Vogt-Koyanagi-Harada syndrome or AAU in ankylosing spondylitis. Hum. Genet. 2013, 132, 1395-1404.

46. Blood eQTL Browser. Available online: http://genenetwork.nl/bloodeqtlbrowser/ (accessed on 1 July 2015).

47. Westra, H.J.; Peters, M.J.; Esko, T.; Yaghootkar, H.; Schurmann, C.; Kettunen, J.; Christiansen, M.W.; Fairfax, B.P.; Schramm, K.; Powell, J.E.; et al. Systematic identification of trans eQTLs as putative drivers of known disease associations. Nat. Genet. 2013, 45, 1238-1243.

48. Dai, R.; Phillips, R.A.; Zhang, Y.; Khan, D.; Crasta, O.; Ahmed, S.A. Suppression of LPS-induced Interferon-gamma and nitric oxide in splenic lymphocytes by select estrogen-regulated microRNAs: A novel mechanism of immune modulation. Blood 2008, 112, 4591-4597.

49. Kim, K.; Madak-Erdogan, Z.; Ventrella, R.; Katzenellenbogen, B.S. A MicroRNA196a2* and TP63 circuit regulated by estrogen receptor- $\alpha$ and ERK2 that controls breast cancer proliferation and invasiveness properties. Horm. Cancer 2013, 4, 78-91.

50. Polman, C.H.; Reingold, S.C.; Edan, G.; Filippi, M.; Hartung, H.P.; Kappos, L.; Lublin, F.D.; Metz, L.M.; McFarland, H.F.; O’Connor, P.W.; et al. Diagnostic criteria for multiple sclerosis: 2005 revisions to the "McDonald Criteria". Ann. Neurol. 2005, 58, 840-846.

51. Sambrook, J.; Fritsch, E.F.; Maniatis, T.; Molecular Cloning: A Laboratory Manual, 2nd ed.; Cold Spring Harbor Laboratory Press: New York, NY, USA, 1989.

52. Favorov, A.V.; Andreewski, T.V.; Sudomoina, M.A.; Favorova, O.O.; Parmigiani, G.; Ochs, M.F. A Markov chain Monte Carlo technique for identification of combinations of allelic variants underlying complex diseases in humans. Genetics 2005, 171, 2113-2121.

53. Apsampler. Available online: http://apsampler.sourceforge.net/ (accessed on 1 July 2015).

(C) 2015 by the authors; licensee MDPI, Basel, Switzerland. This article is an open access article distributed under the terms and conditions of the Creative Commons Attribution license (http://creativecommons.org/licenses/by/4.0/). 